\title{
The sustainable transport pathway: A holistic strategy of Five Transformations
}

\author{
Becky P. Y. Loo (corresponding author) \\ The University of Hong Kong \\ bpyloo@hku.hk
}

\author{
Ka Ho Tsoi \\ The University of Hong Kong \\ jasonf1d@hku.hk
}

\begin{abstract}
In this paper, a holistic strategy of the "Five Transformations" is introduced to offer a comprehensive and synergetic theory to tackle various daunting challenges faced by the transport sector and ultimately pave the way to sustainable transport. The Five Transformations span across city development, the economy, vehicle technology, modal-split and lifestyles at various geographical scales. Building on the current literature and empirical evidence, this paper advocates for fundamental changes in all aspects of the society beyond transportation. To move forward, this paper scrutinizes the association between land-use planning and the Five Transformations. It is clear that land-use policies are important drivers in implementing and reinforcing the policy instruments under the Five Transformations.
\end{abstract}

\section{Article history:}

Received: December 13, 2017

Accepted: April 2, 2018

Available online: November 1, 2018

\section{Introduction}

Transport suggests the mobility of people and goods, and it is one of the key initiatives to foster economic development and support quality of life (Litman, 2007; OECD, 1996). Notwithstanding, a wide range of negative impact, ranging from social, economic and environmental, have been generated with the rapid growth of motorized transport (OECD, 2002; World Bank, 1996). In 2014, the transport sector accounted for around 23 percent of the global carbon emissions where 75 percent of the total was attributable to road transport (IEA, 2016). Transport was also the dominant cause of worldwide fatalities among young people aged 15-29 years in 2012 (WHO, 2015). These have raised fundamental questions about the unsustainability of transport given its rapid development (Banister, 2008; Loo, 2018). Decoupling negative transport externalities from economic growth to achieve comprehensive sustainability has thus emerged as a relatively new paradigm in the past two decades to confront the unsustainable transport development trajectories (Loo \& Banister, 2016; OECD, 2006; Tight, Delle Site, \& Meyer-Rühle, 2004; Velazquez et al., 2015). The essence is that economic growth can be achieved without exacerbating transport conditions. Overall, achieving the three core objectives of sustainability without trade-offs beyond the "minimum thresholds" is central to the discussion of sustainable transport (Litman \& Burwell, 2006).

Copyright 2018 Becky P. Y. Loo \& Ka Ho Tsoi

http://dx.doi.org/10.5198/jtlu.2018.1354

ISSN: 1938-7849 | Licensed under the Creative Commons Attribution - Noncommercial License 4.0

The Journal of Transport and Land Use is the official journal of the World Society for Transport and Land Use (WSTLUR) and is published and sponsored by the University of Minnesota Center for Transportation Studies. This paper is also published with additional sponsorship from WSTLUR. 
Though decoupling transport externalities may be a commonly-shared vision across developed and developing countries, the question remains largely on how to develop a sustainable transport system in the long run without suppressing mobility and all the positive utilities (notably human interactions) associated with it (Loo, 2018). Efficacy of different transport policy instruments in mitigating the associated adverse consequences has been widely discussed; yet, seldom have the wide range of policies been integrated into a holistic strategy that comprises transport governance, higher coordination of various policy instruments, and optimal policy packaging (Banister, 2008; Givoni, Macmillen, Banister, \& Feitelson, 2013; Litman \& Burwell, 2006; Santos, Behrendt, \& Teytelboym, 2010). A holistic strategy needs to consider the transport system as a whole (including the complete life cycle of carbon emissions in producing and deploying the transport infrastructure), and its interface with other nontransport elements, such as energy and urban form (Loo \& du Verle, 2017). Resting on these rationales, this paper aims to propose a synergetic and proactive theory from five perspectives, namely the "Five Transformations" (Loo, 2018). The concept is based on several fundamental tenets. First, "transformation" suggests radical and proactive policy-making that reflects the ultimate underlying motivation to minimize unsustainable transport problems. Second, there is a need to recognize that there are no onesized-fits-all policies; and merely adopting a sustainable transport-related measure might improve the situation in one aspect but worsen the situations in others. Third, a sustainable transport strategy must lie beyond the transport sector and span across city development, land-use planning, technology and human behavior. The transdisciplinary nature indicates that there will hardly be any comprehensive sustainability unless we formulate policies that integrate all relevant constituents in people's daily lives. This paper, therefore, aims to make theoretical advancements in the understanding of sustainable transport and, hence, it does not follow the traditional way comprising methodology and data analysis. Instead, it offers reflections on developing sustainable transport, hoping to inspire researchers and policy-makers of some critical principles and forward-looking solutions. Where appropriate, data are provided to support the arguments. Section 2 describes the Five Transformations. Then, Section 3 scrutinizes the association between the 3Ds of land-use planning (density, diversity and design) and the Five Transformations, arguing that land-use policies are important drivers in implementing and reinforcing the associated policy instruments.

\section{The "Five Transformations" of sustainable transport}

Figure 1 outlines the "Five Transformations" and how these components may pave the way to sustainable transport through decoupling negative transport externalities. The Five Transformations encompass city planning, economic development, vehicle technology, modal-split and individual lifestyles. In Figure 1, they are shown in boxes with blue, green, yellow, orange and purple borders respectively. Under each transformation, there are different policy instruments targeting at various spatial scales (i.e., national, regional, neighborhood and individual). These policy instruments are shown in boxes of the same color to the right of the respective transformations. Integrating multiple spatial scales is paramount in understanding people's travel behavior and promoting sustainable mobility (Bertonlini, le Clercq, \& Kapoen, 2005; Loo, Mehandran, Katagiri, \& Lam, 2017b). In Figure 1, the most important instrument(s) of each transformation is(are) shaded in the same color. These elements suggest prioritized strategies to reinforce the effectiveness of other policies in the respective transformation. The ultimate goal is to achieve decoupling - immaterialization and dematerialization — which describes the decoupling of transport intensity from aggregate economic growth, and the decoupling of undesirable impacts from transport production respectively (Loo \& Banister, 2016). Changing the composition of transport volume such as mode share can also promote dematerialization. 


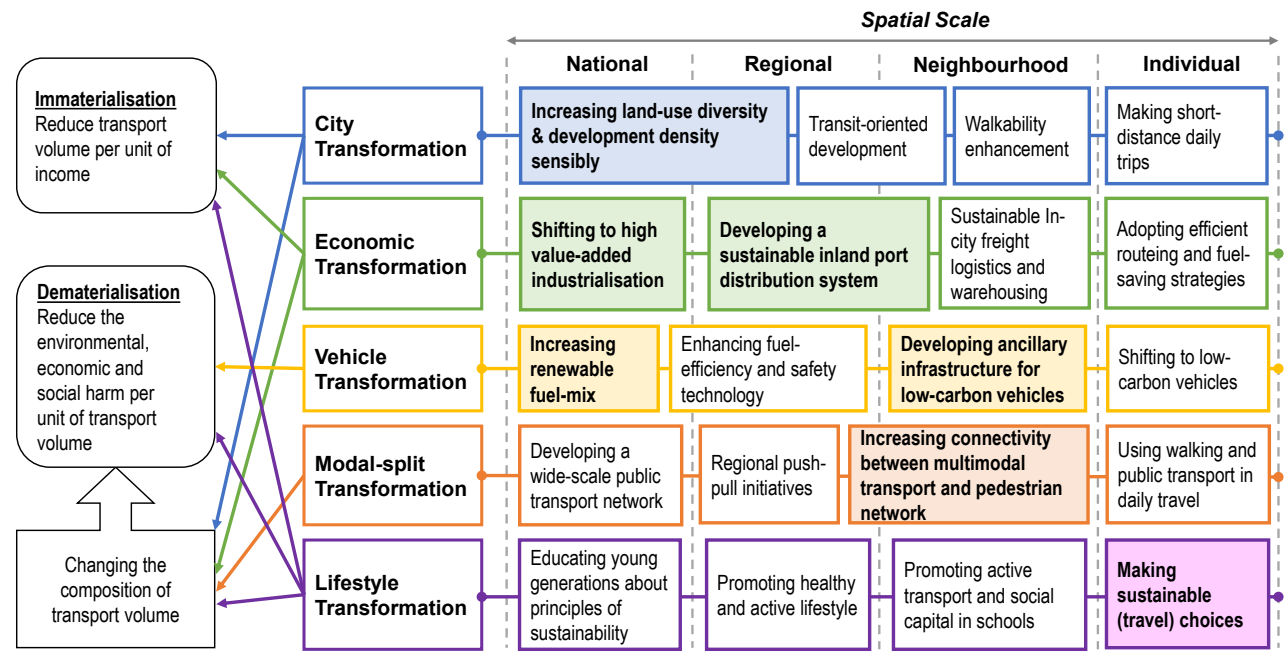

Figure 1: The "Five Transformations" and transport decoupling

\subsection{City transformation}

City transformation indicates the need to initiate better spatial planning and to enhance overall accessibility in cities. Overall, increasing land-use mix and development density sensibly is an essential step to spearhead city transformation. Both elements can provide the much-needed momentum to transitoriented development (TOD) and walkability enhancement, thus promoting short-distance trips.

\subsubsection{Increasing land-use diversity and development density around homes and key activity nodes}

On one hand, increasing land-use diversity can reduce the physical distance between different land uses; on the other hand, increasing development density can enhance individual's accessibility to potential opportunities given the same level of mobility. Should homes and the desired destinations be closer, especially those that are visited on a frequent basis, travel distance and travel time can be saliently reduced. At the regional scale, vast research has concluded that proximity to opportunities supported by compact city development and mixed land-use can generally reduce travel distance (Banister, 2008; Cervero, 2005; Jabareen, 2006). The combined effect of high-density and mixed environment also effectively reduces travel distance in journeys to work (Cervero, 1996; Horner, 2007), school (Marique, Dujardin, Teller, \& Reiter, 2013) and household shopping (Mirmoghtadaee, 2012). This indicates that improving regional accessibility through providing denser opportunities and enhancing land-use mix to incorporate jobs, houses and other public amenities can reduce travel volume and energy consumed in daily travels.

At the national scale, developing a sustainable urban form that balances the distribution of land uses and enhances the accessibility to different spatial clusters is part and parcel. Essentially, a polycentric city development mode which decentralizes job locations and maintains job-housing balance could significantly reduce the minimum commuting travel distance by as much as 80 percent (Loo \& Chow, 2011a). Yet, using polycentrism as a stand-alone policy would only have minimal effects on reducing the total travel volume. For instance, decentralizing employment without spatial matching of jobs between city cores and suburbs will not reduce travel distance (Schwanen, Dieleman, \& Dijst, 2001). Moreover, neighborhoods of higher land-use density and diversity are featured with shorter travel distance, but they 
may attract travelers from other regions with longer travel distance (Manaugh, Miranda-Moreno, \& ElGeneidy, 2010). Hence, it is important to recognize that multiple relevant parameters such as transport network, socio-economic status, and appropriate interventions should be fully integrated to achieve sustainable transport. The imperative of future city planning is to increase the land-use diversity and development density around homes to promote more self-contained communities. Decentralization and job-housing balance are the underpinnings of this form of urbanization (Loo \& Chow, 2011b; Murphy \& Killen, 2011). On the contrary, urban sprawl that separates work locations and residential areas by long distance with highly clustered job opportunities within the urban core should be discouraged.

\subsubsection{Promoting transit-oriented development (TOD)}

Transit-oriented development at the neighborhood scale is a fundamental policy to encourage transit ridership and active transport (Cervero \& Sullivan, 2011; Loo, 2018; Loo \& du Verle, 2017; Litman \& Steele, 2017). In Hong Kong, higher percentages of residents living in TOD neighborhoods take public transit than those living in the non-TOD counterparts (Loo, Chen, \& Chan, 2010). This dichotomy is also found in an Australian study with an emphasis on how personal attitudes may have an impact on the actual modal split (Kamruzzaman, Baker, Washington, \&, Turrell, 2013). Potential reduction of average reduction of trip length is also noticed in TOD areas (Zhang, 2010; Lee, Lee, Park, \& Lee, 2010). Furthermore, as shown in Figure 2, rail-based TOD (RTOD) neighborhoods have higher percentages of walking and metro ridership, and lower percentage of private cars, in both single-mode and multimodal trips than the non-RTOD counterparts (Loo \& du Verle, 2017). This demonstrates the association between RTOD and low-carbon transport.

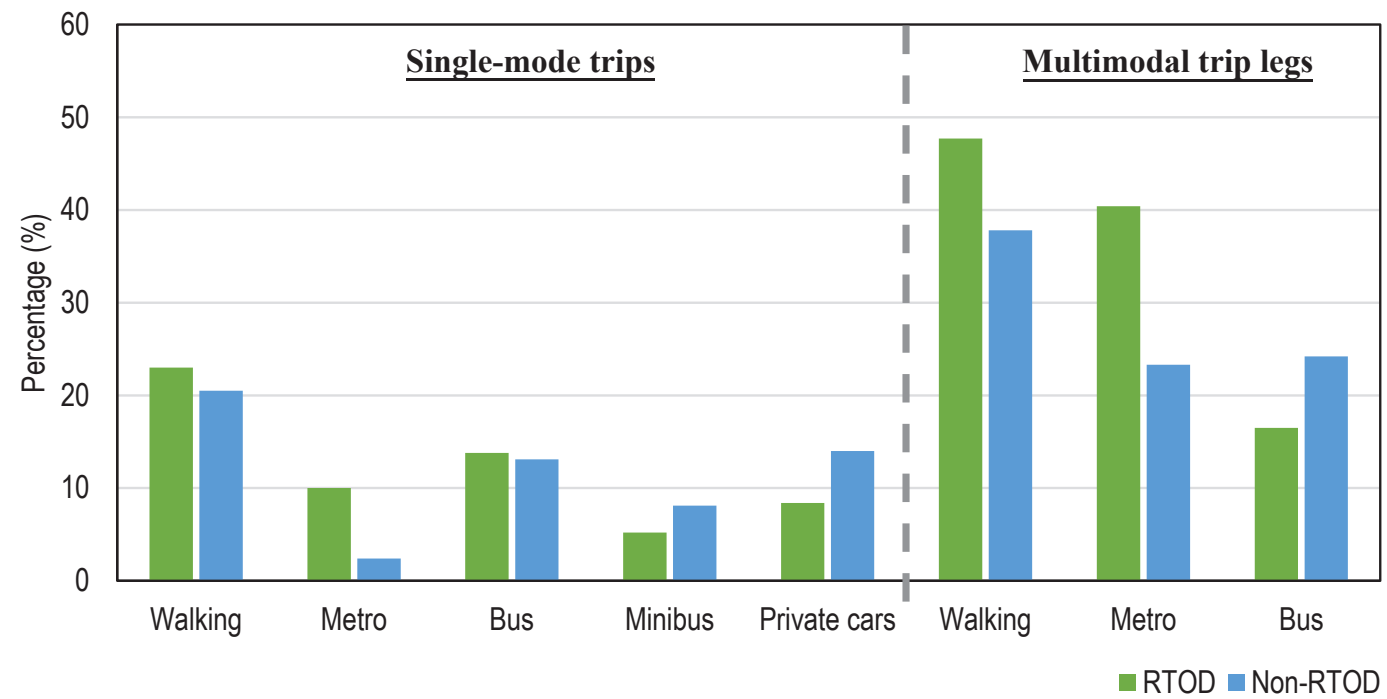

Figure 2: Walking and public transport in RTOD and non-RTOD neighborhoods in Hong Kong in 2011 (modified from Loo \& du Verle, 2017)

Note: 60 rail-based TOD (RTOD) neighborhoods and 60 non-RTOD neighborhoods are investigated. Transport modes that are used in multimodal trips are counted individually in each transport mode. Except for bus-trips, RTOD neighborhoods and the non-RTOD counterparts have significantly different travel mode share $(\mathrm{p}<0.05)$. 
Though TOD is pivotal in sustainable transport planning, we should consider how spatial variations of different places affect the overall efficacy. Xu, Guthrie, Fan, and Li (2017) comment that effective TOD implementation is dependent on the urban contexts. Place-based analysis is essential to the success of TOD. Employing the same strategy to every locality of cities without considering specific neighborhood features would reduce the effectiveness. Loo and du Verle (2017) highlight that TOD is not a uniform strategy applied to all neighborhoods, but it needs to consider the variations of neighborhood characteristics such as the built environment, historical development and socio-demographics. To achieve this principle, a myriad of studies has synthesized the general principles of "3Ds" of density, diversity and design into TOD planning (Cervero \& Kockelman, 1997; Ewing \& Cervero, 2010; Loo $\&$ du Verle, 2017; Renne, 2009). By using the techniques of principal component analysis, Loo and du Verle (2017) concluded that there are five main types of TOD neighborhoods in Hong Kong. Table 1 summarizes the key features of these neighborhoods according to the 3Ds. Based on the various local characteristics, the effectiveness of TOD hinges on tailor-made and relevant place-specific strategies. For instance, a CBD-type TOD neighborhood and an integrated community-type TOD neighborhood can vary significantly in terms of the 3 Ds. The former is characterized by higher transport connectivity and development density, whereas the latter excels in integrating higher residential density near the metro stations with sufficient provision of comprehensive development area (CDA) and retail locations.

Table 1: Five types of TOD neighborhoods in Hong Kong (modified from Loo \& du Verle, 2017)

\begin{tabular}{|c|c|c|c|}
\hline $\begin{array}{l}\text { Type of TOD } \\
\text { neighbourhoods }\end{array}$ & Density & Diversity & Design \\
\hline (a) CBD-type & $\begin{array}{l}\text { - High commercial and } \\
\text { employment intensity } \\
\text { - Mixed commercial- } \\
\text { residential intensity } \\
\text { - High overall develop- } \\
\text { ment intensity }\end{array}$ & $\begin{array}{l}\text { - High land-use diversity } \\
\text { - Provision of different } \\
\text { types of transport }\end{array}$ & $\begin{array}{l}\text { - Dense and well- } \\
\text { connected roads } \\
\text { - Presence of open space } \\
\text { and retail shops }\end{array}$ \\
\hline $\begin{array}{l}\text { (b) Integrated community- } \\
\text { type }\end{array}$ & $\begin{array}{l}\text { - High residential } \\
\text { intensity }\end{array}$ & $\begin{array}{c}\text { - Comprehensive } \\
\text { development }\end{array}$ & $\begin{array}{l}\text { - High transport acces- } \\
\text { sibility } \\
\text { - Abundant retail op- } \\
\text { portunities }\end{array}$ \\
\hline (c) Balanced-type & - & $\begin{array}{l}\text { - High land-use mix } \\
\text { - Diversified housing } \\
\text { types }\end{array}$ & $\begin{array}{l}\text { - High road density } \\
\text { - Presence of open space }\end{array}$ \\
\hline (d) Residential-type & - High population density & $\begin{array}{l}\text { - Large family size } \\
\text { - High household income }\end{array}$ & - \\
\hline (e) Station-type & - & $\begin{array}{l}\text { - High multimodal } \\
\text { connectivity }\end{array}$ & $\begin{array}{l}\text { - Covered walkways } \\
\text { - Fewer expressways } \\
\text { - Presence of retail shops }\end{array}$ \\
\hline
\end{tabular}

Note: $63.41 \%$ of the variance could be explained in the model. 


\subsubsection{Enhancing walkability}

Walkability, as a form of active transport, is an eminent topic in the domain of sustainable transport. Enhancing walkability is embraced as a desirable planning tactic in developing sustainable neighborhoods to encourage walking and reduce transport volume for mechanized modes, thus alleviating social, environmental and economic harms per unit of transport volume (transport decoupling). Walkability is about providing a pleasant pedestrian experience (Loo \& Lam, 2012) and how people and the environment (including the road and other built environment) interact with each other (Loo, Lam, Mehandran, \& Katagiri, 2017a; Wang, Chau, Ng, \& Leung, 2016). Research has identified several critical parameters in walkability enhancement, including land-use diversity, residential density, street connectivity and aesthetics (Frank et al., 2006; Leslie et al., 2005; Saelens, Sallis, Black, \& Chen, 2003). Solely densifying the street network would be ineffective in promoting walking and achieving sustainability goals. To illustrate, insufficient crossing facilities might increase the number of human-vehicular conflicts.

Hence, a full-scale and microscale assessment of walkability is necessary to fully address pedestrians' needs. In general, we can examine walkability through the three dimensions of safety, convenience, and comfort (Loo \& Lam, 2012). An integration of both objective and subjective walkability parameters would be useful to reduce users' dissonance and achieve policy objectives (Carr, Dunsiger, \& Marcus, 2010; Gebel, Bauman, Sugiyama, \& Owen, 2011). Table 2 summarizes several parameters that are deemed the most important to improve pedestrian walking environment in Hong Kong. Among those, convenience of walking to other locations and the comfort of walking environment seem to play a paramount role. Thus, microscale assessments can help bridge users' expectations and planning parameters. Furthermore, walkability assessment should integrate the three-dimensional network (i.e., at-grade pedestrian routes, elevated walkway system (EWS) and underground walkway) which is especially relevant to the compact city environment. Based on people's subjective walkability scores, Figure 3 shows that many pedestrians in urban Hong Kong actually preferred using EWS than at-grade pedestrian network. Yet, trip purpose might affect their choices of using these two types of pedestrian networks. For instance, most respondents preferred using EWS for commuting purpose, while many preferred using at-grade pavement for leisure and recreation purpose.

Table 2: Measures to improve facilities for pedestrian support based on comfort, convenience and comfort

\begin{tabular}{lll}
\hline $\begin{array}{l}\text { Dimensions of walkability assessment } \\
\text { (Loo and Lam, 2012) }\end{array}$ & Measures to improve facilities for pedestrians & $\begin{array}{l}\text { Share of } \\
\text { support (\%) } \\
(\mathbf{n = 5 , 8 2 1 , 9 3 3 )}\end{array}$ \\
\hline Convenience & More travellators & 19.53 \\
Comfort & More covered walkways & 18.24 \\
Comfort & Widening the walkways & 15.56 \\
Convenience & More footbridges and subways & 14.58 \\
Comfort & More air-conditioned walkaways & 12.40 \\
Safety & Vehicle-free green urban areas & 8.88 \\
Safety & Pedestrianisation & 7.43 \\
\hline
\end{tabular}

Note: The average percentages are calculated based on the expanded travel data in Travel Characteristics Survey 2011 (Transport Department, 2011). 


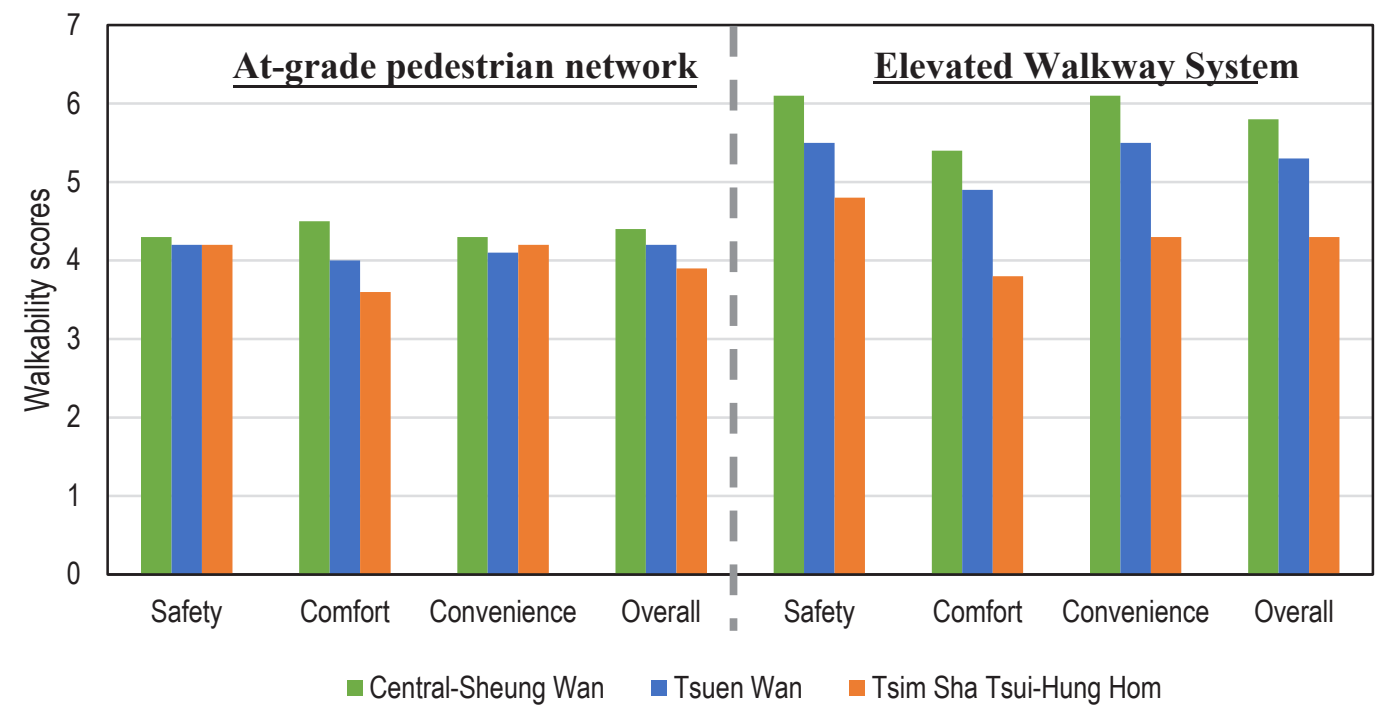

Figure 3: Walkability assessment at the at-grade pedestrian routes and EWS of three pilot areas in Hong Kong Note: Data are extracted from Loo (2017). The pilot study sites are located in urban areas. Walkability scores range from 1 to 7

\subsection{Economic transformation}

Economic transformation aims at reducing the negative externalities from trading and freight logistics in the transport sector. With the growing popularity of e-commerce, there would be upcoming challenges of the sustainability of freight transport. In particular, transport plays an important role in circulating commodities and capital, and it is prevalent in bulk freight logistics of heavy industries (Loo, 2018). Two major strategies are suggested. First, countries should further enhance the composition of high-value added industries in the economy. Second, a sustainable freight logistics network for both port-inland distribution and urban logistics should be built.

\subsubsection{Shifting to high value-added industrialization}

Shifting to higher value-added and less carbon-intensive industries can decrease the transport volume (immaterialization) and negative transport externalities (dematerialization) per unit of income respectively. Indeed, the life cycle of carbon emissions embodied in the export-oriented industry should be closely examined and tackled. For instance, a dual combination of developing new industries with ecofriendly technologies and energy-saving techniques, and reducing the production of heavy-emission industry such as construction material industry is expected to alleviate the environmental impacts (Liang, $\mathrm{Xu}$, Suh, \& Tan, 2013). Quite a number of developing countries have employed low value-added and exported-oriented industrialization as a means to boost economic development, which is not sustainable in the long-run. In China, high energy intensity incurred in the production of low value-added products has given rise to a higher level of carbon embodied in the exported quantities (Qi, Winchester, Karplus, \& Zhang, 2014). In terms of transport, low value-added freight turnover is often featured with higher transport volume intensity per unit of income (Loo, 2018).

\subsubsection{Developing a sustainable port-inland / in-city distribution system}

Under the regime of globalization, the manufacturing production centers are often outsourced to lowcost locations particularly in developing countries. This trend gives rise to the vast market of inter-conti- 
nental maritime logistics. Despite the relatively low environmental impact per freight volume generated by modern maritime vessels, inland distribution of goods (i.e., port-hinterland and raw materials-production points logistics) often create substantial negative transport externalities. Road transport such as trucks is predominantly utilized for inland freight distribution which is highly unsustainable in terms of causing serious traffic congestion, higher carbon emission per freight volume and higher road fatalities. In developing countries, these trucks are usually highly polluting and are not under stringent restriction of emission standards (Loo, 2018). Developing an organized and efficient port-inland distribution system is therefore important to promote the sustainability of freight transport.

Intermodalism is an important strategy to link between container load centers to land-based load centers (Loo \& Liu, 2005). Given strategic break-bulk locations and a clear hub-and-spoke relationship, intermodal freight transshipment might enhance the transport efficiency and reduce externalities. For hub-to-hub networks that connect ports to the inland major load centers or warehouses, railways can be developed to encourage modal shift from trucks to railways or pipelines. Although cost is often the main concern, long travel distance with ample amount of freight (van Kilnk \& van den Berg, 1998), and adequate transport and loading infrastructure aided by economic incentives (Iannone, 2012) are paramount to the development of an intermodal freight system between seaports and interports. Empirically, an intermodal or multimodal network contributes to a drastic reduction of negative transport externalities such as carbon per unit of freight (Craig, Blanco, \& Sheffi, 2013; Kim, Janic, \& van Wee, 2009; Sanchez Rodrigues, Beresford, Pettit, Bhattacharya, \& Harris, 2014). For point-to-point deliveries that are distributed from loading centers to local distribution centers to customers (i.e., last mile and in-city logistics), strategies of re-routing or third-party logistics (3PL) can be integrated as a management strategy to reduce idling capacity and unnecessary travel. For example, 3PLs in the last-mile logistics can enhance the cost effectiveness and reduce carbon emissions (Ji, Gunasekaran, \& Yang, 2014; Mallidis, Dekker, \& Vlachos, 2012). In relation to e-commerce, the rearrangement of urban logistics might also be beneficial to lowering the negative externalities, since the total energy consumption in the supply chain of e-commerce is generally lower than that in the conventional counterpart (Pålsson, Pettersson, \& Hiselius, 2017).

\subsection{Vehicle transformation}

Vehicle transformation is largely driven by technological advancements in the development and use of alternative fuels, the improvement of fuel efficiency, the use of new materials, and the development of autonomous and connected vehicles. Recently, much focus has been put on the development of low-carbon or zero-carbon vehicles that can reduce roadside carbon emissions. However, the upstream carbon emissions brought by the intensive electrification should not be ignored. The composition of renewable power sources in the energy fuel-mix should be further enhanced to realize the benefits of electric vehicles (EVs). In future planning, electrification can also be applied not only to private cars but road public transport such as electric buses. Apart from electricity, biofuels, gaseous fuels, alcohols and ethers can be the alternative energy sources to reduce the carbon emission and air pollution than the traditional sources of diesel and petroleum (Li \& Loo, 2014). Second, enhancing fuel efficiency (measured in terms of fuel used per kilometer driven) is also necessary to maximize the efficacy of energy consumption and reduce carbon emissions. Improvements in fuel efficiency are achievable with different powertrains and drive technologies. Thirdly, high-end research on metallurgy and vehicle manufacturing should be encouraged. For instance, niobium alloys can enhance the strength of steel and reduce the weight of the vehicles simultaneously. On the one hand, the lower weight of vehicles can reduce energy consumption and enhance fuel efficiency. On the other hand, the stronger steel can enhance the overall safety and durability of cars. In terms of EVs, technological breakthroughs in energy-efficient batteries including 
lithium-ion batteries and recently the "titanium niobium oxide" batteries can enhance the energy density and charging speed significantly. Last but not least, the development of autonomous and connected vehicles allows the much wider applications of intelligent transport systems (supported by various other smart technologies, artificial intelligence and big data) to reduce the negative environmental, economic and social transport externalities. In freight logistics, truck platooning, for example, can be applied to reduce fuel consumption. Moreover, the potentials to reduce traffic congestion and fatalities are enormous with better real-time traffic flow and speed optimization, junction controls and traffic collision prevention systems.

\subsection{Modal-split transformation}

The modal-split transformation aims at enhancing the use of public transport and suppressing the growth of automobiles, which reduce the externalities per unit of transport volume (dematerialization). At the national-regional scale, enhancing public transit ridership through TOD is a critical strategy. At the neighborhood-scale, enhancing the connectivity between the pedestrian and public transport networks is also a paramount factor in the promoting sustainable transport modes.

\subsubsection{Enhancing public transit ridership}

To increase transit patronage, developing a sufficient public transport network through TOD is essential to encourage modal shift. Despite the importance of promoting transport modes of low environmental impact per passenger and high carrying capacity per vehicle, the development of bus rapid transit (BRT), light-rail and metro should take into account the cost-effectiveness, city size, demographics structure and pre-existing conditions such as historical development and travel behavior (Loo, 2018). Only when we consider these elements holistically could the financial vitality of the public transport be secured. Another essential aspect to promote public transit is to address the push-pull factors. For "pull" factors, the overall acceptance and legitimacy of public transport need to be enhanced. Batty, Palacin and González-Gil (2015) highlight that an increase of affordability and quality of service are both important, and improvement of its existing conditions (i.e., safety, comfort, reliability and journey time) is far more important than only providing subsidies. "Push" factors management such as congestion pricing and restrictive parking management are also important (Hammadou \& Papaix, 2015). Modal-split should also be further encouraged in inter-regional travel. For instance, high-speed railway (HSR) can be a sustainable alternative to both air and automobile transport for medium- to long-distance intercity travels (Li \& Loo, 2016). A two-level sustainable mobility framework, both intra-regional and interregional, is critical to modal shift by fostering intercity movement whilst enhancing the internal and external connectivity of cities (Loo \& du Verle, 2017). Significant improvement in decarbonization can be realized when the fuel-mix shifts more to cleaner and more renewable energy for short, medium and long-distance trips.

\subsubsection{Enhancing multi-modal connectivity}

A high level of multimodality that encourages seamless travels between different transit locations and destinations is important. Indeed, multi-modal connectivity, including walking, is often overlooked in neighborhood planning. To emphasize, multimodal connectivity should not only be limited to the "convenience" of paratransit (Loo, 2007) or transferring from one motorized mode to another (i.e., BRT terminals next to rail stations or park-and-ride), but also how walking links to the motorized transport modes. It is because pedestrian routes connecting from alighting and boarding locations to origins and destinations, or even between transfer locations, are unavoidable and would critically affect the 
overall travel experience. Empirically, TOD and active transport are mutually supportive, thus creating synergy (Loo, 2018) and encouraging walking as connection trips to transit locations (Huang, Moudon, Zhou, Stewart, \& Saelens, 2017; Noland \& Dipetrillo, 2015; Sun, Zacharias, Ma, \& Oreskovic, 2016). Figure 4 shows that walking distance to the transit locations is also found to be the most important parameter that affects people's desire to use public transport alongside travel time in Hong Kong. In future transport planning, pedestrian network should be integrated to the existing transport network so as to optimize overall route planning of pedestrians.

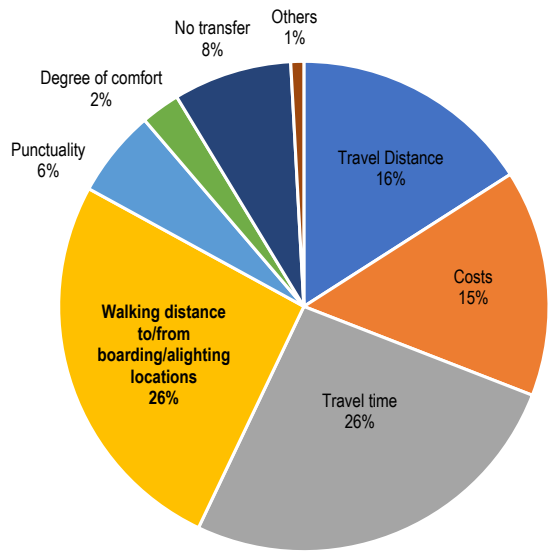

Figure 4: Main factors affecting the choice of taking public transport in Hong Kong

Note: The expanded data indicates a total of 5,821,933 individuals. The average percentages are calculated based on the expanded travel data in Travel Characteristics Survey 2011 (Transport Department, 2011).

\subsection{Lifestyle transformation}

Lifestyle transformation is the most challenging aspect in promoting sustainable transport, because actual behavior is subject to individual variability of beliefs, habits and preferences. Growing lifestyle expectations have enhanced significantly travel demand and mobility needs (Echenique, Hargreaves, Mitchell, \& Namdeo, 2012), but it is high time that we contemplate and rethink whether enhancing mobility without limits is a way to achieve sustainable transport. Enhancing public legitimacy of sustainable transport is one important element in future mobility planning (Banister, 2008). To achieve this, educating our next generation about the principles of sustainability is paramount at the national scale. At the regional-neighborhood scale, promoting healthy lifestyle, active transport and social capital can also help initiate paradigm shift. Most importantly, developing transport infrastructure only provides alternatives but does not necessarily change one's travel behavior. This implies that a people-centered approach is essential to encourage people to make sustainable choices. Policies can first target at the most common travel such as commuting trips. For instance, mobility policies in workplace might somehow encourage changes in commuting behavior (van Malderen et al., 2012), although it might be districtspecific. In addition, lifestyles are interlinked with socio-demographic characteristics such as household income and marital status. A people-based and activity-based framework that takes into account these characteristics is essential to understand how people actually behave in making travel choices (Hildebrand, 2003). 


\section{$3 \quad$ How land-use planning can facilitate the Five Transformations?}

As discussed in Section 2, a holistic strategy of "Five Transformations" should be incorporated to develop sustainable transport. However, the challenge remains that there are different policy instruments in different "systems" at various spatial scales, but a lack of focus and integration might largely limit its efficacy. It is necessary to examine how the above framework can be feasibly implemented. This section argues that land-use planning, as an inseparable component of sustainable transport, can act as the impetus to support and reinforce the efficacy of policy instruments under the Five Transformations. Essentially, land uses are evaluated based on their functionality to different human activities such as housing, working, transport and recreational use (OECD, 2005). The structure of land-use also manifests the general interests of various stakeholders, and thus indirectly influences the components of human wellbeing (Bourne, 1976). Proper land-use planning can change a neighborhood's functionality and affect travel behavior. In this research, strategies of land-use planning are divided into the 3Ds of diversity, density and design. We use 3Ds instead of 6Ds (distance, destination and demand) (as suggested in Ogra \& Ndebele, 2014) because 3Ds are the most relevant to our discussion and a proper set of 3Ds can have indirect impact on distance, destination and demand. Land-use diversity and density have been discussed in Section 2.1.1. Land-use design refers to the enhancement of relationship between people and the built environment, and how various land uses can reduce conflicts between stakeholders (Cervero \& Kockelman, 1997). Figure 5 proposes a package of implementation tools in sustainable transport and showcases how the 3Ds of land-use planning can foster sustainable transport and encourages both sustainable travel behavior and sustainable freight practices. Critically, land-use planning and policy instruments of the Five Transformations are mutually reinforcing. The relationships are discussed below.

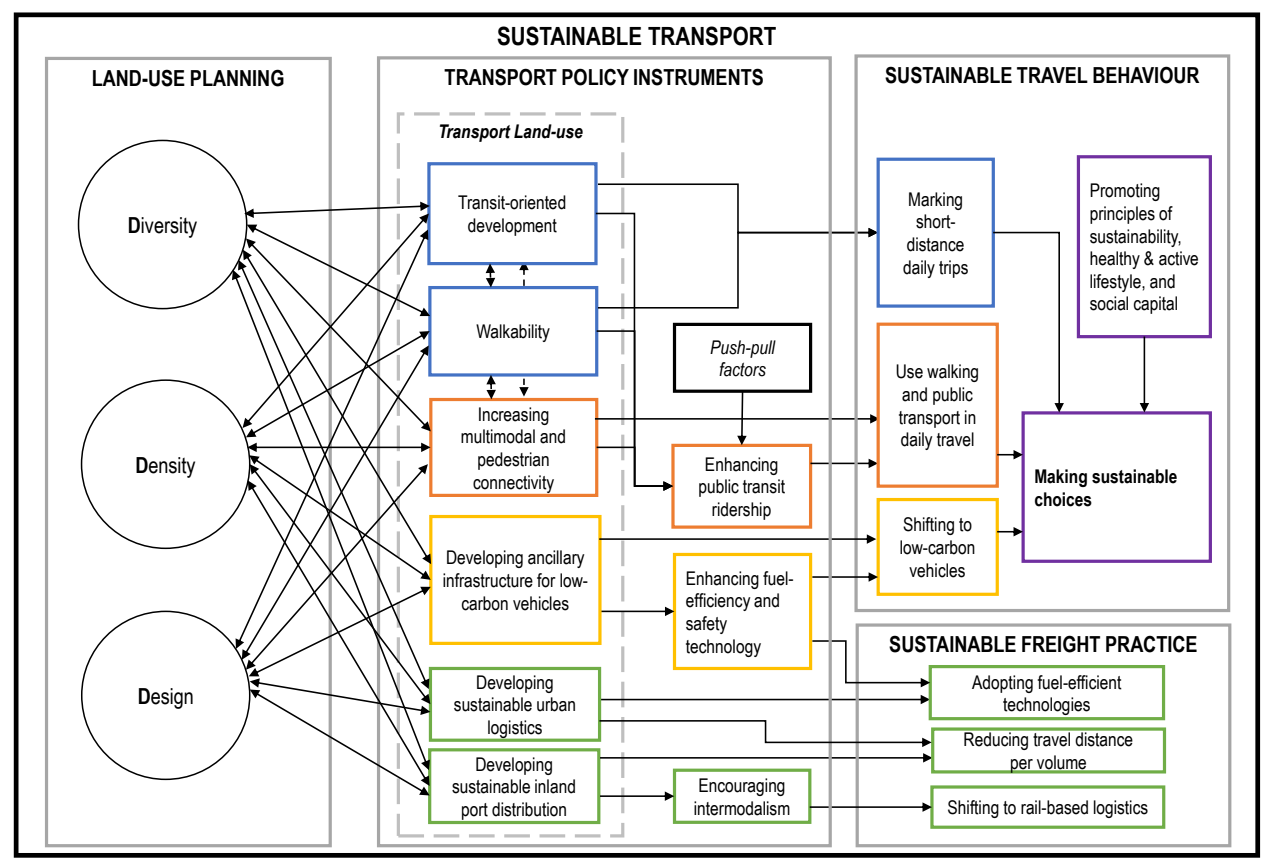

Figure 5: A package of "implementation tools" initiated by 3Ds of land-use planning 


\subsection{Land-use planning, TOD and walkability}

Land-use planning, TOD and walkability always mutually reinforce one another. As succinctly described by Renne (2009), TOD is primarily concerned with the built environment, mixed land use and compact development. Moreover, it is related to how the built environment promotes transit connectivity and walking (Ewing \& Cervero, 2010; Jacobson \& Forsyth, 2008; Loo \& du Verle, 2017; Renne, 2009). Higher levels of land-use density and diversity generally enhance proximity to different locations and shorten travel distance. Moreover, they also produce collateral effects such as promoting a wider use of public and active transport (Cervero \& Kockelman, 1997; Cervero \& Sullivan, 2011; Litman \& Steele, 2017). With RTOD, the train station can act as a district "magnet" that retains residents' daily activities within the neighborhood. As for walking, a 500-meter buffer around a transit location, which is approximately around 10-minute walking time, is favorable to walking (Loo, Chen, \& Chan, 2010; Loo, Cheng, \& Nichols, 2017).

From another perspective, the synergetic effect of TOD and walkability in return reinforces the 3D's of land-use, because it contributes to higher accessibility and more rigorous development. The mutual reinforcement is observed in Loo, Cheng and Nichols (2017). In Figure 6, it is noticeable that population density, land-use density, residential and commercial development have increased in both greenfield and brownfield sites in 5-year time after the opening of different rail stations in Hong Kong. The escalation in greenfield sites suggests that RTOD is an effective strategy to boost local economy and property development in areas of new development. On the other hand, rail multimodal and walking multimodal have also increased after 10-year operation of the new railway station. The higher increase in brownfield sites suggests that RTOD can increase public transport ridership even in more mature neighborhoods. Overall, RTOD has the potential to transform urban forms and encourage more use of public transit. At the city-scale, this can also help promote polycentrism that balances opportunities and increases density in RTOD neighborhoods. This explains why TOD is not only a transport concept, but more importantly the process of shaping a neighborhood with higher land-use accessibility and vibrancy.

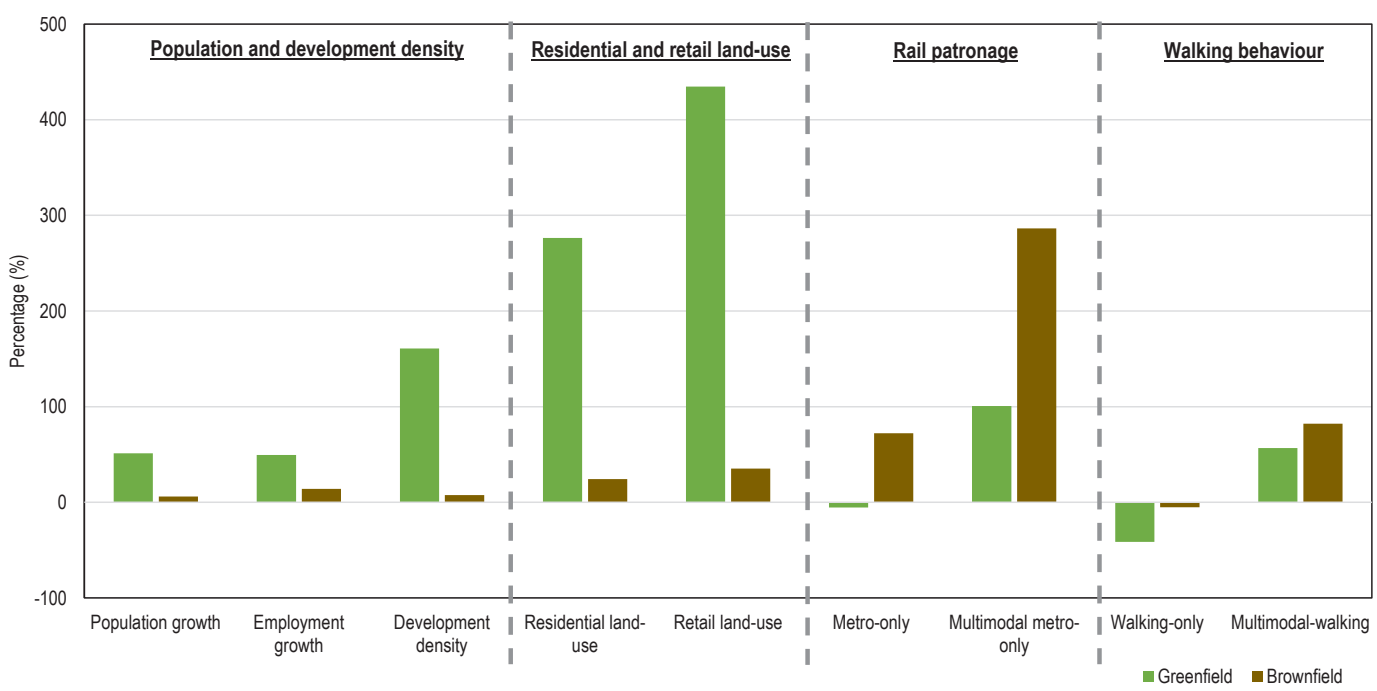

Figure 6: Changes of land-use density, rail patronage and walking behavior in greenfield sites and brownfield sites of Hong Kong (modified from Loo, Cheng, \& Nichols, 2017)

Note: 60 RTOD neighborhoods and 60 non-RTOD neighborhoods are investigated. Changes of density of land-use, residential and retail land-use are calculated based on 5 years after the operation of the station. Changes of rail patronage and walking behavior are calculated based on 10 years after the operation of the station. 


\subsection{Land-use planning and sustainable freight transport}

Increasing land-use diversity and density helps develop a sustainable port-inland distribution network. To recall, the potential intermodalism is built heavily on the factors of relatively long distance and sufficiently high freight volume. A more compact city development with intermixing of land-use can facilitate the emergence of logistics hubs, because more trading of commodities by individuals (residential land use) and corporations (commercial and industrial land use) within a more concentrated region would be anticipated. This paves the way to the development of interports or urban consolidation centers near city centers with railway lines connecting to seaports. Empirically these centers are effective to reduce travel distance per volume in urban areas (Allen, Browne, Woodburn, \& Leonardi, 2012). Shorter travel distance and lower idling capacity in the last-mile journey is also expected because of a clustering of delivery locations. In terms of design, loading centers within the downtown area is also feasible if reserved parking spaces for lorries are provided and pedestrian connectivity to these centers is enhanced (Muñuzuri, Larrañeta, Onieva, \& Cortés, 2005). The inland-port and urban logistics might also reinforce the development density and diversity in the city. Furthermore, e-commerce has enhanced the importance of last-mile deliveries. The location of collection points and pick-up stores is therefore critical. For instance, proper land-use planning, such as decent transit connectivity and walkability, denser distribution of collection points and mixed-use development for multi-users logistics, is associated with enhancing efficiency of last-mile deliveries (Allen et al., 2018). The spatial relationship between transport land-use for logistics and other land uses should also be considered. As logistic hubs are usually not favored by residential and commercial land-use due to their relatively high negative externalities (i.e., air and noise pollution), the loading or consolidation centers, either situated at the city outskirts or downtowns, need to be planned to reduce their negative impact to the surrounding land uses. For instance, the use of storage boxes in neighborhoods and smaller-scale dispatches at non-peak hours should be considered. Meeting the logistics demand in urban areas whilst not posing other negative externalities is essential to sustainable urban logistics.

\subsection{Land-use planning and advanced vehicle technologies}

The utilization of low-carbon or zero-carbon vehicles needs to be reinforced by land-use policies. First, compact city development signifies that the spatial coverage of and space devoted to charging facilities can be significantly reduced. Second, the design of transport land-use is important to the green technologies. To illustrate, using EVs requires the provision of electric charging stations in residential and non-home locations. As technology advances, the constraints of costs, driving range and battery life have already been greatly relaxed. Yet, a most urgent question remains unsolved - how to develop enough charging infrastructure (both plug-in facilities and wireless panels) under a compact city development to accommodate the shift to EVs? Although a denser and diversified land-use pattern can reduce car ownership, there would still be a certain number of car trips (including passengers and logistics). A policy to attract car buyers to choose EVs requires enough incentives, including a wider and denser coverage of charging facilities. Therefore, the spatial distribution of charging locations supported by land-use coordination is relevant and important. In Hong Kong, the availability of charging infrastructure has been the second most critical factor in governing people's intention to buy or not to buy EVs, superseding the attributes of range and life of batteries (Table 3). Essentially, the allocation of charging stations in different land uses requires an integration of activity patterns, charging time and parking availability (Zhang, Brown, \& Samuelsen, 2013). In particular, time constraints are important in affecting the actual refueling behavior for EV users (Liu \& Sun, 2014), further indicating that some land uses which usually involve longer activity time, such as residential housing and workplace, should be identified 
as the major targets for EV charging stations. Further research should match travelers' spatiotemporal activity patterns so as to better allocate resources for setting up charging facilities. While space is limited in a compact city environment, the integration of parking and charging facilities would be essential to fully realize the advantage of EVs.

Table 3: Reasons for buying or not buying hybrid or electric vehicles in Hong Kong

\begin{tabular}{lllc}
\hline $\begin{array}{l}\text { Main reasons for not buying hybrid or elec- } \\
\text { tric vehicles }\end{array}$ & $\%$ & $\begin{array}{l}\text { The most important factors affecting the deci- } \\
\text { sion of buying an electric vehicle } \\
(\mathbf{n}=\mathbf{4 1 , 1 5 0 )}\end{array}$ & \% \\
\hline No experience / confidence & 25.89 & Price & 27.66 \\
\hline Inadequate charging stations & 22.33 & Location of charging stations & 19.11 \\
\hline No second-hand options & 13.81 & Continuous driving distance & 15.71 \\
Inadequate power & 11.71 & Costs of installing own charging facilities & 11.92 \\
Troubles of changing batteries & 11.19 & Cost of batteries & 8.92 \\
Too few models & 9.54 & None of these & 7.69 \\
Too expensive to replace batteries & 5.03 & Market price of second-hand electric vehicles & 5.25 \\
& & Environmentally-friendly & 3.75 \\
\hline
\end{tabular}

Note: The average percentages are calculated based on the expanded travel data in Travel Characteristics Survey 2011 (Transport Department, 2011).

\subsection{Land-use planning and multi-modal connectivity}

Appropriate land-use design can enhance the connectivity between a multimodal transport network for mechanized modes and the pedestrian routes. As argued earlier, increasing level of walkability is associated with a higher land-use density and diversity. However, enhancing the connection between public transport and the pedestrian network requires more microscopic investigations. In other words, enhancing walkability might increase physical activity and the propensity of walking, but it does not necessarily facilitate the use of public transport. Therefore, studies of operational behavior of pedestrians that integrates their route choice and navigation at transit stations on the basis of route sections (Porter, Hamdar, \& Daamen, 2017) is fundamental in planning future TOD neighborhoods. Some studies start to pay attention to the walking routes that connect public transit locations, and they summarize that more comprehensive development with commercial development on the ground-level and a mix of residential land use surrounding the main transit can enhance the connectivity of the dual network (Kim, 2015; Park, Choi, \& Lee, 2017). This signifies that mixed commercial land-use is imperative to people's walking experience and tendency take public transit. In return, higher pedestrian flows can reinforce the land-use density and diversified different opportunities. Planners should incorporate pedestrians' expectations along the journey to and from public transit locations. Moreover, more research is needed to incorporate the three-dimensional walking network and surrounding land-use for analyzing actual travel behavior. Making use of underground or elevated space to enhance the connectivity to pedestrian routes and transit locations is duly considered. For instance, underground walkways featured with shopping activities and service sectors can maintain pedestrian flows (Cui, Allan, Taylor, \& Lin, 2015).

\subsection{Land-use planning and travel behavior}

Land-use planning should not just consist of statutory measures that force people to adopt sustainable behavior; instead, it should be a holistic package of soft and hard policies that provide alternative travel options to every resident within the neighborhood. It is emphasized that land-use planning is not, and 
should not be, the only policy that modifies and shapes travel behavior. While land-use planning principles do offer huge potentials in discouraging unsustainable travel behavior, the complexity of travel behavior should be duly considered in transport planning (Maat, van Wee, \& Stead, 2005). Based on the above analysis, land-use planning strategies can support the transformations for sustainable transport mainly at the regional and neighborhood scale. However, these policies are important to improve the experience of travelers so as to lead to voluntary changes of travel behaviors.

\section{Conclusion}

To summarize, this paper conceptualizes the theory of "Five Transformations", including city, economy, vehicle technology, modal-split and lifestyle, in promoting sustainable transport. It puts emphasis on how to formulate a holistic set of policy instruments on different spatial scales to decouple the negative transport externalities to encounter the sustainability issues ahead. Moreover, land-use planning and sustainable transport are always interlinked, and this research offers insights on how land-use planning can be an important driver and a mechanism for reinforcing the transport policies under the scope of Five Transformations, and hence encourage behavioral change and achieving the ultimate goal of sustainable transport. To address the complexity of travel behavior with variations in socio-demographic, activity patterns and lifestyles, this paper also highlights the importance of adopting both people-oriented and place-based approaches alongside land-use and sustainable transport planning. The tenets of future sustainable transport planning are two-fold. In terms of city development, an overarching statement and vision of compact and diversified land-use planning with well-connected transport and pedestrian network needs to be established. In terms of promoting sustainable travel choices, a more bottom-up strategy that considers users' expectations and examines the underlying factors of realized travel behavior should be put forward.

\section{Acknowledgements}

This paper was built on the keynote presentation of the first author titled 'From negative transport externalities to sustainability: What are the ways forward?' in the World Symposium on Transport and Land Use Research 2017 (WSTLUR 2017) from July 3 to July 6 in Brisbane, Queensland, Australia. She is indebted to the comments and suggestions received during the conference and from the reviewers. 


\section{References}

Allen, J., Browne, M., Woodburn, A. \& Leonardi, J. (2012). The role of urban consolidation centers in sustainable freight transport. Transport Reviews, 32(4), 473-490.

Allen, J., Piecyk, M., Piotrowska, M., McLeod, F., Cherrett, T., Ghali K., ... Austwick, M. (2018). Understanding the impact of e-commerce on last-mile light goods vehicle activity in urban areas: The case of London. Transportation Research Part D: Transport and Environment, 61, 325-338.

Banister, D. (2008). The sustainable mobility paradigm. Transport Policy, 15, 73-80.

Batty, P., Palacin, R., \& González-Gil, A. (2015). Challenges and opportunities in developing urban modal shift. Travel Behavior and Society, 2(2), 109-123.

Bertolini, L., le Clercq, F., \& Kapoen, L. (2005). Sustainable accessibility: A conceptual framework to integrate transport and land use plan-making. Two test-applications in the Netherlands and a reflection on the way forward. Transport Policy, 12(3), 207-220.

Bourne, L. S. (1976). Urban structure and land-use decisions. Annals of the Association of American Geographers, 66(4), 531-547.

Carr, L. J., Dunsiger, S. I., \& Marcus, B. H. (2010). Walk score ${ }^{\mathrm{TM}}$ as a global estimate of neighborhood walkability. American Journal of Preventive Medicine, 39(5), 460-463.

Cervero, R. (1996). Mixed land uses and commuting: Evidence from the American Housing Survey. Transportation Research Part A, 30(5), 361-377.

Cervero, R. (2005). Accessible cities and regions: A framework for sustainable transport and urbanism in the 21st century. Berkeley, CA: University of California Berkeley, Center for Future Urban Transport: A Volvo Center of Excellence.

Cervero, R., \& Kockelman, K. (1997). Travel demand and the 3Ds: Density, diversity and design. Transportation Research Part D, 2(3), 199-219.

Cervero, R., \& Sullivan, C. (2011). Green TODs: Marrying transit-oriented development and green urbanism. International Journal of Sustainable Development and World Ecology, 18(3), 210-218.

Craig, A. J., Blanco, E. E., \& Sheffi, Y. (2013). Estimating the CO2 intensity of intermodal freight transportation. Transportation Research Part D: Transport and Environment, 22, 49-53.

Cui, J., Allan, A., Taylor, M. A. P., \& Lin, D. (2015). An examination of pedestrian trip behavior in underground pedestrian systems. International Planning Studies 20(3), 209-227.

Echenique, M. H., Hargreaves, A. J., Mitchell, G., \& Namdeo, A. (2012). Growing cities sustainably. Does urban form really matter? Journal of the American Planning Association, 78(2), 121-137.

Ewing, R. \& Cervero, R. (2010). Travel and the built environment. Journal of the American Planning Association, 76(3), 1-31.

Frank, L. D., Sallis, J. F., Conway, T. L., Chapman, J. E., Saelens, B. E., \& Bachman, W. (2006). Many pathways from land use to health: Associations between neighborhood walkability and active transportation, body mass index, and air quality. Journal of the American Planning Association, 72, 75-87.

Gebel, K., Bauman, A. E., Sugiyama, T., \& Owen, N. (2011). Mismatch between perceived and objectively assessed neighborhood walkability attributes: Prospective relationships with walking and weight gain. Health Place, 17(2), 519-524.

Givoni, M., Macmillen, J., Banister, D., \& Feitelson, E. (2013). From policy measures to policy packages. Transport Reviews, 33(1), 1-20.

Hammadou, H., \& Papaix, C. (2015). Policy packages for modal shift and CO2 reduction in Lille, France. Transportation Research Part D, 38, 105-116.

Hildebrand, E. D. (2003). Dimensions in elderly travel behavior: A simplified activity-based model using lifestyle clusters. Transportation, 30(3), 280-306. 
Horner, M. (2007). A multi-scale analysis of urban form and commuting change in a small metropolitan area (1990-2000). The Annals of Regional Science, 41(2), 315-333.

Huang, R., Moudon, A. V., Zhou, C., Stewart, O. T., \&. Saelens, B. E. (2017). Light rail leads to more walking around station areas. Journal of Transport and Health, 6, 201-208.

Iannone, F. (2012). The private and social cost efficiency of port hinterland container distribution through a regional logistics system. Transportation Research Part A: Policy and Practice, 46(9), 1424 1448 .

International Energy Agency (IEA). (2016). $\mathrm{CO}_{2}$ emissions from fuel combustion highlights. Paris: IEA. Jabareen, Y. R. (2006). Sustainable urban forms: Their typologies, models, and concepts. Journal of Planning Education and Research, 26(1), 38-52.

Jacobson, J., \& Forsyth, A. (2008). Seven American TODs: Good practices for urban design in transitoriented development projects. Journal of Transport and Land Use, 1(2), 51-88.

Ji, G., Gunasekaran, A., \& Yang, G. (2014). Constructing sustainable supply chain under double environmental medium regulations. International Journal of Production Economics, part B, 147, 211-219.

Kamruzzaman, Md., Baker, D., Washington, S., \& Turrell, G. (2013). Residential dissonance and mode choice. Journal of Transport Geography, 33, 12-28.

Kim, H. (2015). Walking distance, route choice, and activities while walking: A record of following pedestrians from transit stations in the San Francisco Bay area. Urban Design International, 20(2), $147-157$.

Kim, N. S., Janic, M., \& van Wee, B. (2009). Trade-off between carbon dioxide emissions and logistics costs based on multi-objective optimization. Transportation Research Record: Journal of the Transportation Research Board, 2139, 107-116.

Lee, S., Lee, S., Park, D., \& Lee, C. (2010). Analysis of travel patterns between road and transit-oriented development areas. Journal of Advanced Transportation, 44(1), 3-10.

Leslie, E., Saelens, B., Frank, L., Owen, N., Bauman, A., Coffee, N., \& Hugo, G. (2005). Residents' perceptions of walkability attributes in objectively different neighborhoods: A pilot study. Health \& Place, 11, 227-236.

Li, L., \& Loo, B. P. Y. (2014). Alternative and transitional energy sources for urban transportation. Current Sustainable/Renewable Energy Reports, 1(1), 19-26.

Li, L., \& Loo, B. P. Y. (2016). Railway development and air patronage in China, 1993-2012: Implications for low-carbon transport. Journal of Regional Science, 57(3), 507-522.

Liang, S., Xu, M., Suh, S., \& Tan, R. R. (2013). Unintended environmental consequences and cobenefits of economic restructuring. Environmental Science and Technology, 47(22), 12894-12902.

Litman, T. (2007). Developing indicators for comprehensive and sustainable transport planning. Transportation Research Record, 2017, 10-15.

Litman, T., \& Burwell, D. (2006). Issues in sustainable transportation. International Journal of Global Environmental Issues, 6(4), 331-347.

Litman, T., \& Steele, R. (2017). Land use impacts on transport: How land-use factors affect travel behavior. Victoria, BC: Victoria Transport Policy Institute.

Liu, K., \& Sun, X. H. (2014). Considering the dynamic refueling behavior In locating electric vehicle charging stations. ISPRS Annals of the Photogrammetry, 2(2), 41-46.

Loo, B. P. Y. (2007). The role of paratransit: Some reflections based on the experience of residents' coach services in Hong Kong. Transportation, 34, 471-486.

Loo, B. P. Y. (2017). Consultancy services on walkability in pedestrian planning and enhancement of pedestrian network in Hong Kong. Hong Kong: University of Hong Kong Institute of Transport Studies.

Loo, B. P. Y. (2018). Unsustainable transport and transition in China. London: Routledge. 
Loo, B. P. Y., \& Banister, D. (2016). Decoupling transport from economic growth: Extending the debate to include environmental and social externalities. Journal of Transport Geography, 57, 134-144.

Loo, B. P. Y., Chen, C., \& Chan, E. T. H. (2010). Rail-based transit-oriented development: Lessons from New York City and Hong Kong. Landscape and Urban Planning, 97, 202-212.

Loo, B. P. Y., Cheng, A. H. T., \& Nichols, S. L. (2017). Transit-oriented development on greenfield versus infill sites: Some lessons from Hong Kong. Landscape and Urban Planning, 167, 37-48.

Loo, B. P. Y., \& Chow, A. S. Y. (2011a). Jobs-housing balance in an era of population decentralization: An analytical framework and a case study. Journal of Transport Geography, 19, 552-562.

Loo, B. P. Y., \& Chow, A. S. Y. (2011b). Spatial restructuring to facilitate shorter commuting: An example of the relocation of Hong Kong International Airport. Urban Studies, 48(8), 1681-1694.

Loo, B. P. Y., \& du Verle, F. (2017). Transit-oriented development in future cities: Towards a two-level sustainable mobility strategy. International Journal of Urban Sciences, 21(supp.1), 54-67.

Loo, B. P. Y., \& Lam, W. W. Y. (2012). Geographic accessibility around elderly health care facilities in Hong Kong: A micro-scale walkability assessment. Environment and Planning B: Planning and Design, 39(4), 629-646.

Loo, B. P. Y., Lam, W. W. Y, Mehandran, R., \& Katagiri, K. (2017a). How is the neighborhood environment related to the health of seniors in Hong Kong, Singapore and Tokyo? Some insights for promoting aging-in-place. Annals of the American Association of Geographers, 107(4), 812-828.

Loo, B. P. Y., \& Liu, K. (2005). A geographical analysis of potential railway load centers in China. Professional Geographer, 57(4), 558-579.

Loo, B. P. Y., Mehandran, R., Katagiri, K., \& Lam, W. W. Y. (2017b). Walking, neighborhood environment and quality of life among older people. Current Opinion in Environmental Sustainability, 25, $8-13$.

Mallidis, I., Dekker, R., \& Vlachos, D. (2012). The impact of greening on supply chain design and cost: A case for a developing region. Journal of Transport Geography, 22, 118-128.

Manaugh, K., Miranda-Moreno, L. F., \& El-Geneidy, A. M. (2010). The effect of neighborhood characteristics, accessibility, home-work location, and demographics on commuting distances. Transportation, 37, 627-646.

Marique, A. F., Dujardin, S., Teller, J., \& Reiter, S. (2013). School commuting: The relationship between energy consumption and urban form. Journal of Transport Geography, 26, 1-11.

Matt, K., van Wee, B., \& Stead, D. (2005). Land use and travel behavior: Expected effects from the perspective of utility theory and activity-based theories. Environment and Planning B: Planning and Design, 32, 33-46.

Mirmoghtadaee, M. (2012). The relationship between land use, socioeconomic characteristics of inhabitants and travel demand in new towns - a case study of Hashtgerd New Town (Iran). International Journal of Urban Sustainable Development, 4(1), 39-62.

Muñuzuri, J., Larrañeta, J., Onieva, L., \& Cortés, P. (2005). Solutions applicable by local administrations for urban logistics improvement. Cities, 22(1), 15-28.

Murphy, E., \& Killen, J. E. (2011). Commuting economy: An alternative approach for assessing regional commuting efficiency. Urban Studies, 48(6), 1255-1272.

Noland, R. B., \& DiPetrillo, S. (2015). Transit-oriented development and the frequency of modal use. The Journal of Transport and Land Use, 8(2), 21-44.

OECD. (1996, March). Towards Sustainable Transportation proceedings, Vancouver, British Columbia, Canada.

OECD. (2002). OECD guidelines towards environmentally sustainable transport. Paris: Organization for Economic Co-operation and Development. 
OECD. (2005). Handbook of national accounting: Integrated environmental and economic accounting. Paris: Organization for Economic Co-operation and Development.

OECD. (2006). Decoupling the environmental impacts of transport from economic growth. Paris: Organization for Economic Co-operation and Development.

Ogra, A., \& Ndebele, R. (2014, October-November). The role of 6Ds: Density, diversity, design, destination, distance, and demand management in transit oriented development (TOD). Paper presented at the Neo-International Conference on Habitable Environments, San Diego, USA.

Pålsson, H., Pettersson, F., \& Hiselius, L. W. (2017). Energy consumption in e-commerce versus conventional trade channels - insights into packaging, the last mile, unsold products and product returns. Journal of Cleaner Production 164, 765-778.

Park, S., Choi, K., \& Lee, J. S. (2017). Operationalization of path walkability for sustainable transportation. International Journal of Sustainable Transportation, 11(7), 471-485.

Porter, E., Hamdar, S. H., \& Daamen, W. (2017). Pedestrian dynamics at transit stations: An integrated pedestrian flow modeling approach. Transportmetrica A: Transport Science, 14(5-6), 468-483.

Qi, T., Winchester, N., Karplus, V. J., \& Zhang, X. (2014). Will economic restructuring in China reduce trade-embodied CO2 emissions? Energy Economics, 42, 204-212.

Renne, J. L. (2009). From transit-adjacent to transit-oriented development. Local Environment, 14, $1-15$.

Saelens, B. E., Sallis, J. F., Black, J. B., \& Chen, D. (2003). Neighborhood-based differences in physical activity: An environment scale evaluation. American Journal of Public Health, 93(9), 1552-1558.

Sanchez Rodrigues, V., Beresford, A., Pettit, S., Bhattacharya, S., \& Harris, I. (2014). Assessing the cost and CO2 impacts of rerouting UK import containers. Transportation Research Part A: Policy and Practice, 61, 53-67.

Santos, G., Behrendt, H., \& Teytelboym, A. (2010). Part II: Policy instruments for sustainable road transport. Research in Transportation Economics, 28, 46-91.

Schwanen, T., Dieleman, F. M., \& Dijst, M. (2001). Travel behavior in Dutch monocentric and policentric urban systems. Journal of Transport Geography, 9(3), 173-186.

Sun, G., Zacharias, J., Ma, B., \& Oreskovic, N. M. (2016). How do metro stations integrate with walking environments? Results from walking access within three types of built environment in Beijing. Cities, 56, 91-98

Tight, M. R., Delle Site, P., \& Meyer-Rühle, O. (2004). Decoupling transport from economic growth: Towards transport sustainability in Europe. European Journal of Transport and Infrastructure Research, 4(4), 381-404.

Transport Department (TD). (2011). 2011 Travel characteristics survey (TCS 2011). Hong Kong: Transport Department, Hong Kong SAR.

van Kilnk, H. A., \& van den Berg, G. C. (1998). Gateways and intermodalism. Journal of Transport Geography, 6(1), 1-9.

van Malderen, L., Jourquin, B., Thomas, I., Vanoutrive, T., Verhetsel, A., \& Witlox, F. (2012). On the mobility policies of companies: What are the good practices? The Belgian case. Transport Policy, 21, $10-19$.

Velazquez, L., Munguia, N. E., Will, M., Zavala, A. G., Verdugo, S. P., Delakowitz, B., \& Giannetti, B. (2015). Sustainable transportation strategies for decoupling road vehicle transport and carbon dioxide emissions. Management of Environmental Quality: An International Journal, 26(3), 373-388.

Wang, Y., Chau, C. K., Ng, W. Y., \& Leung, T. M. (2016). A review on the effects of physical built environment attributes on enhancing walking and cycling activity levels within residential neighborhoods. Cities, 50, 1-15. 
World Bank. (1996). Sustainable transport: Priorities for policy reform. Development in practice. Washington, DC: The World Bank.

World Health Organization (WHO). (2015). Global status report on road safety 2015. Geneva: World Health Organization.

Xu, W., Guthrie, A., Fan, Y., \& Li, Y. (2017). Transit-oriented development: Literature review and evaluation of TOD potential across 50 Chinese cities. Journal of Transport and Land Use, 10(1), 743-762.

Zhang, L., Brown, T., \& Sameulsen, S. (2013). Evaluation of charging infrastructure requirements and operating costs for plug-in electric vehicles. Journal of Power Sources, 240, 515-524.

Zhang, M. (2010). Can transit-oriented development reduce peak-hour congestion? Transportation Research Record: Journal of the Transportation Research Board, 2174, 148-155. 